\title{
Wetting and Interfacial Reaction Investigations of Coke/Slag Systems and Associated Liquid Permeability of Blast Furnaces
}

\author{
Tae Wook KANG, Sushil GUPTA, N. SAHA-CHAUDHURY and Veena SAHAJWALLA
}

Sustainable Materials Processing Program, School of Materials Science and Engineering, The University of New South Wales, Sydney, 2052, Australia. E-mail: tae-wook-kang@hanmail.net; veena@unsw.edu.au

(Received on December 9, 2004; accepted on July 13, 2005)

\begin{abstract}
An interfacial study between metallurgical coke and synthetic slags representing typical slag chemistry of bosh regions of an operating blast furnace was conducted at $1500^{\circ} \mathrm{C}$ using a horizontal laboratory furnace. The wetting characteristics of coke with slag was studied by measuring dynamic contact angle of sessile droplet of slag on coke substrate, while reaction kinetics of interface was monitored by measuring the amount of $\mathrm{CO}$ and $\mathrm{CO}_{2}$ gases with the help of infrared analyzer. The interface chemistry was also examined by SEM/EDS/EPMA. The study demonstrated that coke wettability was strongly dependent both on the slag composition as well as coke chemistry such that low basicity $\left(\mathrm{CaO} / \mathrm{SiO}_{2}\right)$ of slag, that is high amounts of oxides of silicon enhanced the wetting propensity of slag. The study further showed that the wettability of coke with slag was found to improve with increased extent of gasification, and was attributed to higher ash content of partially gasified cokes. The $\mathrm{CO} / \mathrm{CO}_{2}$ measurements of off gases from the reacting chamber were used to demonstrate that slag wettability with coke was primarily controlled by the kinetics of reduction of metal oxides at the slag/coke interface particularly that of silica. The study demonstrates that in addition to slag composition, coke properties could also influence the liquid permeability of lower zone of the blast furnace, and hence needs attention while optimizing the bosh slag composition for high productivity blast furnace operation.
\end{abstract}

KEY WORDS: blast furnace; coke; slag composition; reactivity; wetting; slag-coke interaction; interfacial reaction.

\section{Introduction}

Due to increasing environmental pressure, steel industries worldwide are adopting many strategies to improve the production efficiency of the blast furnace. The strategies to minimize energy losses and lower cost of the molten iron product include low slag volume and high PCI (Pulverized Coal Injection) operation. Therefore, the factors affecting the liquid and gas permeability particularly in lower part of the blast furnace are of continuous interest to blast furnace operators. Specifically liquid permeability is more important during practice of high productivity operation due to its strong influence on the blast furnace efficiency. Liquid permeability is known to be a strong function of fluidity of slag in lower parts of the blast furnace. Often, fluidity of the blast furnace slag is controlled by adjusting the slag chemistry through modification of burden practice such as changing the amount of supplementary material and the quality of sinter. For instance, the basicity $\left(\mathrm{CaO} / \mathrm{SiO}_{2}\right)$ and magnesium oxide content of slag are modified in accordance with expected slag behaviour in lower part of the blast furnace. In past, influence of slag viscosity and surface tension related phenomena on liquid permeability of the blast furnace has been extensively investigated. ${ }^{1-3)}$ However, at high temperatures exceeding $1500^{\circ} \mathrm{C}$, the viscosity does not change significantly within the narrow range of variation of slag chemistry, hence could have small influence on the fluidity in lower part of the blast furnace. Recently, PCI char property has been shown to influence the char/slag interactions. ${ }^{4,5)}$ Thus, it is reasonable to expect that coke properties and its interactions with molten slag from burden materials could also influence the liquid permeability in lower zone of the blast furnace. Therefore, there is a need to understand the mechanisms of coke/slag interactions and their potential implications on the liquid permeability of a blast furnace.

Wettability is essentially a spontaneous response at the interface when a liquid is brought into contact with a solid surface. Often, wetting is measured in terms of contact angle, $\theta$, a characteristic angle formed at the solid-liquidgas interface as a result of the intermolecular forces acting on the liquid drop. Completely non-wetting is believed to occur at a contact angle of $180^{\circ}$, while for a practical purpose solid is considered to be non-wetting if the contact angle is more than $\left.90^{\circ} .{ }^{6}\right)$ On the other hand, complete wetting is said to occur when the contact angle is $0^{\circ}$, when the liquid spontaneously spreads over the solid surface. The wetting behaviour of a liquid on a solid in a given gaseous environment depends upon the state of equilibrium of the system. The wetting behaviour is also dependent on the nature of solid/liquid system namely reactive or non-reactive systems. In a non-reactive system, no reaction or transport phenomena is involved at the interface, and the wettability is governed by the balance of the interfacial energies between the solid-liquid, solid-gas and liquid-gas phases. The equilibrium contact angle is characterized by classical Young's equation, ${ }^{7)}$ and is related to surface energies as shown in Eq. (1). 


$$
\cos \theta=\frac{\gamma_{\mathrm{SG}}-\gamma_{\mathrm{LS}}}{\gamma_{\mathrm{LG}}}
$$

Where $\gamma_{\mathrm{SG}}, \gamma_{\mathrm{LS}}$ and $\gamma_{\mathrm{LG}}$ are the surface and interfacial tensions at solid-gas, solid-liquid and liquid-gas interfaces, respectively. For a reactive system, the solid phase actively participates in the reaction at the interface, then the driving force $\left(\gamma_{\mathrm{SG}}-\gamma_{\mathrm{LS}}\right)$ for wetting could increase due to the contribution of Gibbs free energy, which could be through mass transfer across the interface or formation of new phases at the interface. ${ }^{8)}$ As the slag/coke/gas is a reactive system, the contact angle and consequently the wetting behaviour will be influenced by the reaction of slag/coke carbon as well as in-situ reaction of coke ash/coke carbon. Consequently, slag and carbon compositions of interface will change continuously over the reaction duration, and hence wetting will be function of time often referred as dynamic wetting.

In slag/carbonaceous systems, reduction of iron oxide and silica are known to be the main reactions affecting wettability. ${ }^{4,5)}$ On the other hand, the same oxides of silicon and iron are the main reducible oxides present in the bosh slag in lower part of the blast furnace. In addition, coke also contains oxides of iron and silicon which could also participate in reduction reactions. Therefore, it is imperative to look at the some of blast furnace reactions relating to silica and iron reduction phenomena. For example, direct reduction of molten iron oxide by solid carbon is known to occur according to Eq. (2). ${ }^{10)}$

$$
\mathrm{FeO}(\mathrm{l})+\mathrm{C}(\mathrm{s})=\mathrm{Fe}(\mathrm{l})+\mathrm{CO}(\mathrm{g})
$$

Indirect reduction of molten iron oxide occurs by intermediates gas phases of carbon (CO) as shown in Eq. (3), while gasification of carbon occurs by well known Boudouard reaction provided in Eq. (4).

$$
\begin{gathered}
\mathrm{FeO}(\mathrm{l})+\mathrm{CO}(\mathrm{g})=\mathrm{Fe}(\mathrm{l})+\mathrm{CO}_{2}(\mathrm{~g}) \\
\mathrm{C}(\mathrm{s})+\mathrm{CO}_{2}(\mathrm{~g})=2 \mathrm{CO}(\mathrm{g}) \ldots . .
\end{gathered}
$$

In powdery mixtures of silica and carbon, silica starts reacting around $1400^{\circ} \mathrm{C}$ in neutral environment following Eqs. (5) and (6). ${ }^{11)}$

$$
\begin{aligned}
& \left(\mathrm{SiO}_{2}\right)+\mathrm{C}(\mathrm{s})=\mathrm{SiO}(\mathrm{g})+\mathrm{CO}(\mathrm{g}) \\
& \mathrm{SiO}(\mathrm{g})+2 \mathrm{C}(\mathrm{s})=\mathrm{SiC}(\mathrm{s})+\mathrm{CO}(\mathrm{g})
\end{aligned}
$$

Combining Eqs. (5) and (6),

$$
\left(\mathrm{SiO}_{2}\right)+3 \mathrm{C}(\mathrm{s})=\mathrm{SiC}(\mathrm{s})+2 \mathrm{CO}(\mathrm{g})
$$

There are two stable condensed phases coexisting in each reaction, i.e., $\mathrm{SiO}_{2}$ and $\mathrm{C}$ or $\mathrm{C}$ and $\mathrm{SiC}$. System freedom is 2 and temperature and partial pressure can determine the equilibrium phases. In the presence of molten iron, silicon is transferred to iron according to Eqs. (8) and (9). ${ }^{12)}$

$$
\begin{aligned}
& \mathrm{SiO}(\mathrm{g})+\mathrm{C}(\mathrm{s})=[\mathrm{Si}]+\mathrm{CO}(\mathrm{g}) \\
& \left(\mathrm{SiO}_{2}\right)+2 \mathrm{C}(\mathrm{s})=[\mathrm{Si}]+2 \mathrm{CO}(\mathrm{g})
\end{aligned}
$$

Coke/slag reactions are well known to be responsible for generating $\mathrm{SiO}$ gas in a blast furnace. ${ }^{12)}$ Particularly in-situ reduction of coke silica is believed to be main mechanism of $\mathrm{SiO}$ formation in a blast furnace. ${ }^{13)}$ Initially formed $\mathrm{SiO}$ gas is reoxidised to silica during combustion and mixed in a pure and finely divided form to the ascending gas stream and later filtered by coke bed. The actual reduction of silica occurs as the metal runs over the impregnated coke picking up silicon at the same time as it dissolves carbon. ${ }^{14)}$

Viscous slag is believed to impair the counter current flow of gas and liquid permeability in bosh regions in a blast furnace. The viscosities of $\mathrm{CaO}-\mathrm{SiO}_{2}-\mathrm{Al}_{2} \mathrm{O}_{3}-\mathrm{MgO}-$ $\mathrm{FeO}$ system were measured under a range of bosh slag composition $\left(\mathrm{CaO} / \mathrm{SiO}_{2} \quad 1.15-1.6\right.$ and 3.5-10 mass \% $\mathrm{MgO}){ }^{1)}$ The study indicated that slag viscosity was minimum in a basicity range of 1.3 , and low amounts of $\mathrm{MgO}$ in the slag was suggested in order to improve liquid permeability of the bosh region. ${ }^{1)}$ However, at temperatures exceeding $1450^{\circ} \mathrm{C}$, the slag chemistry had a little impact on the viscosity particularly in the narrow composition range of slag under study. ${ }^{2)}$ All previous studies regarding slag liquid permeability have primarily focused on the slag viscosity, and none of the studies have considered the influence and implication of coke and slag interfacial reactions.

Recently, char/slag interaction has been studied, ${ }^{5,15-17)}$ but there is only limited work available on study of interfacial wetting behaviour and in coke/slag systems. In addition, the role of composition of slag and carbonaceous materials and its influence on the reduction reactions is not fully understood. Therefore, there is need to understand the interfacial reaction between coke and slag, particularly the kinetics of reduction of metal oxides at the interface and their consequences on wetting propensity of slag and hence their possible impact on liquid permeability in the blast furnace.

An interfacial study of phenomena associated with coke and slag at a high temperature of $1500^{\circ} \mathrm{C}$ was conducted with a special focus on the evolution of wettability with time. The primary objective of this study is to identify the factors relating to slag chemistry affecting wettability and the reaction kinetics of slag/coke system as a function of basicity of slag in a composition range similar to those often seen in lower parts of an operating blast furnace. The influence of coke gasification on the slag wettability is also investigated.

The slag wettability with coke was investigated in a horizontal furnace following classical sessile drop method. The reduction kinetic of oxides at the coke/slag interface was investigated by monitoring the composition of gases released during reaction. The interface chemistry was examined by using SEM/EDS/EPMA in order to explain the dynamic nature of wettability/contact angles in the slag/coke system. The reduction kinetic of oxides at interface is related to differences in wettability of various slag/coke systems. Implications of coke/slag interaction on the liquid permeability of the blast furnace are also discussed.

\section{Experimental}

\subsection{Coke and Slag Samples}

An industrial coke sample used in operating blast furnaces of POSCO Pohang works was selected for this study. Table 1 provides the chemical composition of raw coke A. In addition, raw coke $\mathrm{A}$ was reacted with $100 \% \mathrm{CO}_{2}$ at $1000^{\circ} \mathrm{C}$ in TGA furnace in order to obtain a set of partially gasified coke samples. For simplicity, the gasified coke samples are designated as coke A-20, A-40 and A-60, which correspond to $20 \%, 40 \%$ and $60 \%$ weight loss of coke sample during gasification respectively. These partially gasified coke samples were used as substrates in order to examine the effect of extent of gasification on the slag wettability. Table 2 provides the carbon and ash content of the gasified coke samples, and overall ash composition in cokes is available in Table 3. Wettability of one slag sample with synthetic graphite (containing $0.01 \%$ ash) and silicon car- 
Table 1. Chemical composition of coke A expressed as oxide (wt \%) of ash. The ash content of coke A was $11.2 \mathrm{wt} \%$ while the CSR (coke strength after reaction) and CRI (coke reactivity index) values were 67.3 and 22.4 respectively.

\begin{tabular}{|c|c|c|c|c|c|c|c|c|c|c|}
\hline \multicolumn{10}{|c|}{ Oxides in coke ash (wt.\%) } \\
\hline $\mathrm{SiO}_{2}$ & $\mathrm{Al}_{2} \mathrm{O}_{3}$ & $\mathrm{CaO}$ & $\mathrm{MgO}$ & $\mathrm{Fe}_{2} \mathrm{O}_{3}$ & $\mathrm{P}_{2} \mathrm{O}_{5}$ & $\mathrm{MnO}$ & $\mathrm{TiO}_{2}$ & $\mathrm{ZnO}$ & $\mathrm{K}_{2} \mathrm{O}$ & $\mathrm{Na}_{2} \mathrm{O}$ \\
\hline 55.4 & 32.3 & 2.3 & 1.1 & 3.7 & 0.9 & 0.02 & 2.3 & 0.1 & 0.9 & 0.18 \\
\hline
\end{tabular}

Table 2. Carbon and ash content of partially gasified coke samples.

\begin{tabular}{|c|c|c|c|c|}
\hline \multirow{2}{*}{ Content } & \multicolumn{4}{|c|}{ Level of coke gasification } \\
\cline { 2 - 5 } & $\begin{array}{c}\text { Coke A } \\
\text { (Raw coke) }\end{array}$ & $\begin{array}{c}\text { Coke A-20 } \\
(20 \% \text { weight Loss) }\end{array}$ & $\begin{array}{c}\text { Coke A-40 } \\
(40 \% \text { weight Loss })\end{array}$ & $\begin{array}{c}\text { Coke A-60 } \\
(60 \% \text { weight Loss })\end{array}$ \\
\hline Carbon (\%) & 88.8 & 81.2 & 75.9 & 69.8 \\
\hline Ash (\%) & 11.2 & 18.8 & 24.1 & 30.2 \\
\hline
\end{tabular}

Table 3. Overall ash composition in cokes.

\begin{tabular}{|c|c|c|c|c|c|c|c|c|c|c|c|}
\hline & $\mathrm{SiO}_{2}$ & $\mathrm{Al}_{2} \mathrm{O}_{3}$ & $\mathrm{CaO}$ & $\mathrm{MgO}$ & $\mathrm{Fe}_{2} \mathrm{O}_{3}$ & $\mathrm{P}_{2} \mathrm{O}_{5}$ & $\mathrm{MnO}$ & $\mathrm{TiO}_{2}$ & $\mathrm{ZnO}$ & $\mathrm{K}_{2} \mathrm{O}$ & $\mathrm{Na}_{2} \mathrm{O}$ \\
\hline Coke A & 6.20 & 3.62 & 0.26 & 0.12 & 0.41 & 0.10 & - & 0.26 & 0.01 & 0.10 & 0.02 \\
\hline Coke A-20 & 10.42 & 6.07 & 0.43 & 0.21 & 0.70 & 0.17 & - & 0.43 & 0.02 & 0.17 & 0.03 \\
\hline Coke A-40 & 13.35 & 7.78 & 0.55 & 0.27 & 0.89 & 0.22 & - & 0.55 & 0.02 & 0.22 & 0.04 \\
\hline Coke A-60 & 16.73 & 9.75 & 0.69 & 0.33 & 1.12 & 0.27 & 0.01 & 0.69 & 0.03 & 0.27 & 0.05 \\
\hline
\end{tabular}

Table 4. Chemical composition of slag samples (wt\%).

\begin{tabular}{|c|c|c|c|c|c|c|}
\hline \multirow{2}{*}{ Slag No. } & \multicolumn{5}{|c|}{ Composition (\%) } & \multirow{2}{*}{$\mathrm{CaO} / \mathrm{SiO}_{2}$} \\
\cline { 2 - 6 } & $\mathrm{CaO}$ & $\mathrm{SiO}_{2}$ & $\mathrm{MgO}$ & $\mathrm{Fe}_{2} \mathrm{O}_{3}$ & $\mathrm{Al}_{2} \mathrm{O}_{3}$ & \\
\hline 1 & 39.0 & 39.4 & 5.6 & 5.9 & 10.1 & 1.0 \\
\hline 2 & 43.8 & 34.6 & 5.6 & 5.9 & 10.1 & 1.3 \\
\hline 3 & 47.8 & 30.6 & 5.6 & 5.9 & 10.1 & 1.6 \\
\hline
\end{tabular}

bide $(85 \% \mathrm{SiC}, 15 \% \mathrm{Si})$ was also studied in order to clarify the effect of coke ash content and the presence of $\mathrm{SiC}$ at the slag/coke interface on the slag/coke wettability. A range of synthetic slag samples were prepared to simulate the bosh slag composition by using commercial chemical reagents. The chemical reagents were mixed and melted in a platinum crucible at $1600^{\circ} \mathrm{C}$ in a muffle furnace. Molten slag was quenched followed by manual crushing. This process was repeated three times in order to obtain a homogenous slag sample. The chemical homogeneity of slag samples was determined by XRF measurements of slag samples as indicated in Table 4. The chemical composition of iron phase is expressed as $\mathrm{Fe}_{2} \mathrm{O}_{3}$. Basicity extent of slags $\left(\mathrm{CaO} / \mathrm{SiO}_{2}\right)$ was from 1.0 to 1.6 . Iron oxide and alumina content of all slags were fixed $6 \%$ and $10 \%$ in each slag.

\subsection{Sessile Drop Tests}

Slag/coke reactions were studied in a laboratory scale, horizontal tube resistance furnace using the sessile drop approach. Coke or graphite samples were used as substrate while slag samples were melted by contact heating on the carbon substrate to make a sessile drop. The synthetic graphite was cut into square disc of dimensions of $20 \times 20 \times$ $5 \mathrm{~mm}$ from a solid cubical block, and was polished using emery paper up to 1200 grit size $(14 \mu \mathrm{m})$. Coke sample was ground using Ring mill and sieved to under $34 \mu \mathrm{m}$ for homogeneous composition. Coke powders were compacted to the same dimension using steel die without any binder, in order to obtain a flat and uniform substrate for testing slag wettability. Four grams of powder coke was placed into steel die and compacted under a hydraulic load of 5, 4, and 3 tonnes, holding the die at each load for one minute.

Figure 1 shows the schematic of the experimental set up used for measuring dynamic contact angle between slag and coke as a function of time. The horizontal tube furnace with an internal diameter of $50 \mathrm{~mm}$ was made of double walled, vacuum insulated stainless steel tubes equipped with a fan cooler to dissipate heat. Approximately $0.25 \mathrm{~g}$ of slag piece was located on coke substrate and kept in an alu-

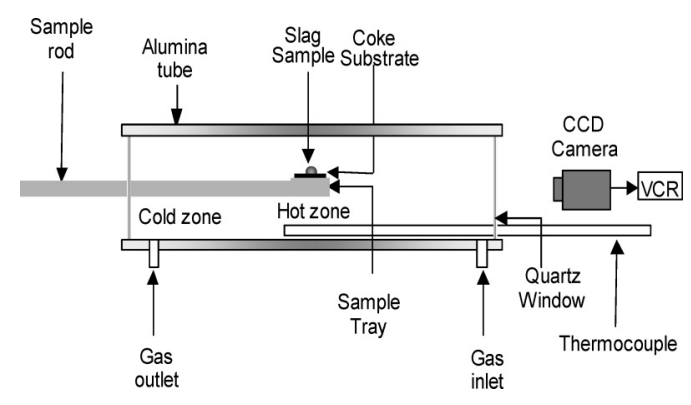

Fig. 1. Schematic diagram of the experimental set up used for measuring contact angle and the rate of reduction of silica.

mina specimen holder. The sample assembly was connected to stainless steel rod and was held in the cold zone of the furnace until the furnace temperature reached $1500^{\circ} \mathrm{C}$. Subsequently, the assembly was pushed into the hot zone of the furnace. The furnace was purged with argon throughout the duration of the experiment. Argon flow rate was controlled by a mass flowmeter. A high quality, high resolution charge-coupled device (CCD) camera fitted with an IRIS lens was used to capture the live in-situ changes in the shapes of sessile droplet of slag. The output from the camera was connected to a video cassette recorder (VCR) and a television (TV) monitor to visually observe and record the entire process as a function of time. A time-date generator was also used in the system to display the time intervals on the image. This allows the sessile drop images of slag on carbonaceous material, to be captured as a function of time. An IR (infrared analyser) gas analyzer was used to measure the $\mathrm{CO} / \mathrm{CO}_{2}$ concentrations of the outlet gas mixture. A time delay of 40 to $60 \mathrm{~s}$ occurred during recording gas recording by IR, and was attributed to the time required for gases to travel from the reaction site to the IR cell. All the data relating to IR gas measurements was corrected for this time lag before plotting against time. A series of blank runs were also conducted on carbonaceous materials without any slag. The volume of $\mathrm{CO}$ and $\mathrm{CO}_{2}$ was converted into mole 
units using standard gas equation. Data collected during blank runs of coke substrates was subtracted from the data obtained using both slag/coke together. The contribution to off-gases from carbonaceous material due to adsorbed oxygen and in-situ reactions was assumed to remains unaltered in both cases.

For each test, contact angles were recorded up to $5 \mathrm{~h}$. Specially designed computer software was used to measure the contact angle from the video captured images, on the basis of a curve-fitting exercise as detailed elsewhere. ${ }^{18)}$

\subsection{Microscopic Analysis of Interface (SEM/EPMA)}

The slag droplets were examined under a FESEM (Field Emission Scanning Electron Microscope) and analyzed using EDS (Energy Dispersive Spectroscopy) for observing chemical changes involved and also to identify the formation of any new reaction products. The EPMA (Electron Probe Micro Analyzer) was used to determine the concentration profiles of key elements. EPMA mapping conditions for recording of the analytical signal of the sample are: accelerating voltage of $15 \mathrm{kV}$, beam size of $2 \mu \mathrm{m}$, beam current of $100 \mathrm{nA}$ and sampling time of $10 \mathrm{~ms}$. Conditions of FESEM are: accelerating voltage of $20 \mathrm{kV}$, beam current of $200 \mathrm{pA}$ and magnification of $\times 1500$. For making a sample for observing the slag/coke interface for FESEM/EPMA analysis, a slag droplet on coke substrate cooled to room temperature was collected after reaction. This was moulded using a thermosetting resin at $120^{\circ} \mathrm{C}$, and cut to reveal a cross-section of the slag droplet so that the surface of sample shows the interface of slag droplet and coke substrate. Then, this sample is metallographically polished using alumina paste. The polished sample is ultrasonically cleaned and $\mathrm{Au}$ coated to facilitate examination under all the microscopic analysis. The analysed size of the sample was $1.40 \times$ $0.96 \mathrm{~mm}$.

\section{Results}

\subsection{Measurements of Dynamic Contact Angle/Wetta- bility}

Figure 2 indicates the variation of contact angle as a function of time of three slags varying in basicity. The basicity of Slags 1, 2 and 3 is 1.0, 1.3 and 1.6 respectively. Slag 3 did not display any significant change in contact angle with time. Throughout the duration of experiment, the contact angles of Slag 3 were always high $\left(>100^{\circ}\right)$, and could be considered as highly non-wetting slag as the contact angles were greater than $90^{\circ}$. Figure 2 further shows that dynamic wetting of Slag 2 was sluggish compared to Slag 1 such that time lags between slag droplet formation and start of contact angle declining of Slag 1 and Slag 2 were 50 and $100 \mathrm{~min}$. Subsequently, Slag 1 approaches to transition limits of partial wetting $\left(<90^{\circ}\right)$ much faster compared to Slag 2 (about $80 \mathrm{~min}$ for Slag 1 and $160 \mathrm{~min}$ for
Slag 2). Slag 1 continued to display greater wetting tendency with coke A throughout the test, when compared with other Slags 2 and 3, the contact angle of Slag 1 dropped rapidly to less than $20^{\circ}$ in $130 \mathrm{~min}$, which is approximately half of the time taken by Slag 2 to acquire similar contact angle. This implies that wettability of Slag 1 with Coke A is better than Slags 2 and 3. Figure 3 shows the video images of sessile drops of Slags 1, 2 and 3 after $2 \mathrm{~h}$ (200 min) to illustrate the visual differences in their droplet profiles. Slag droplet 1, which displays the least contact angle $\left(<10^{\circ}\right)$ spreads most on the Coke A substrate. Thus, it is apparent decreasing the basicity of slag always leads to improvement in the wetting propensity of slag towards coke. Lower slag basicity means higher amounts of $\mathrm{SiO}_{2}$ content in the slag. These results are in good agreement with previous studies who had also reported improved wetting of natural graphite and coal chars by high silica slag. ${ }^{5,19)}$

In real blast furnace, as the coke descends towards lower part of the blast furnace, extent of gasification and ash content could increase and vary at different part of the furnace. ${ }^{20)}$ Coke samples were gasified to different extents to study the impact of increased ash content as a consequence of gasification. To illustrate this aspect of slag/coke wettability, only one slag sample (Slag 2) was used for wettability test with cokes of different extents of gasification. Figure 4 shows the variation of contact angle of Slag 2 with four samples of coke A, representing different extents of gasification. Wetting of Slag 2 with Coke A-60 starts improving dynamically within a relatively shorter period of 45 min compared to time periods of 60,75 and 105 min for Coke A-40, Coke A-20 and Coke A respectively. Coke A60 shows the most rapid transition from non-wetting to wetting i.e. the shortest time ( $45 \mathrm{~min}$ ) to acquire a contact angle of $90^{\circ}$. Coke A has the least ash content $(11.2 \%)$ while Coke A-60 has highest ash content of around $30 \%$. This is expected as the relative percentage ash in coke increases with higher extent of gasification. The improved wettability of the higher ash coke sample suggests that the presence of ash in the coke has a strong influence on the contact angle.

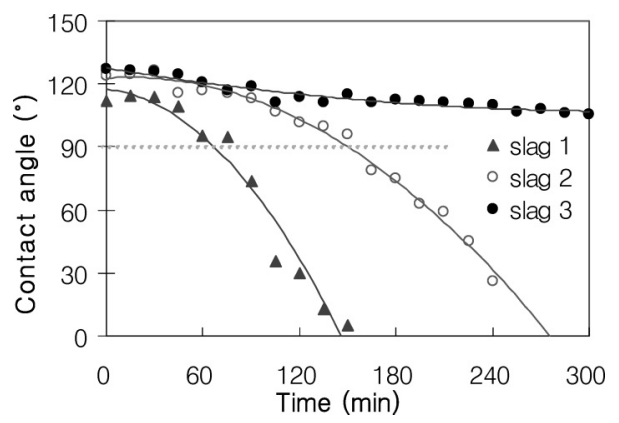

Fig. 2. Variation of contact angle with time for different slag on raw Coke A substrate at $1500^{\circ} \mathrm{C}$. The basicity of Slags 1 , 2 and 3 is in the range of $1.0,1.3$ and 1.6 respectively.

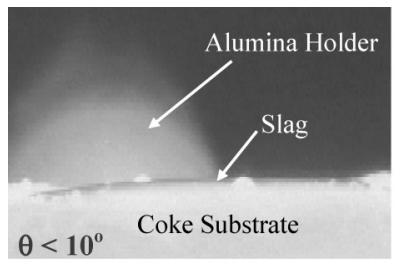

(a)

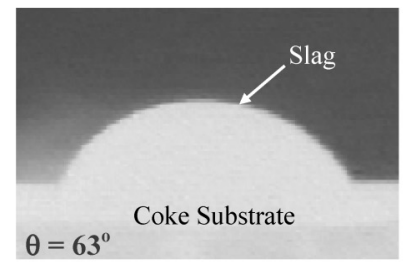

(b)

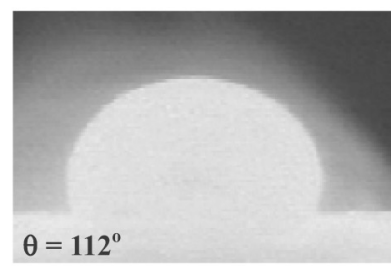

(c)

Fig. 3. Video images of sessile drop of Slag 1 (a), Slag 2 (b) and Slag 3 (c) on Coke A substrate after 200 min of interaction at $1500^{\circ} \mathrm{C}$. 


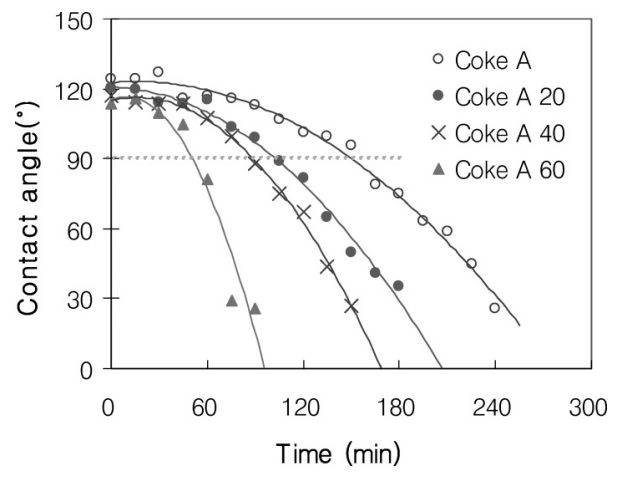

Fig. 4. Variation of contact angle of Slag 2 with time at $1500^{\circ} \mathrm{C}$ on substrates of partially gasified cokes. Coke A represents unreacted coke while Coke A-20, A-40 and A-60 represent the coke samples reacted with $100 \% \mathrm{CO}_{2}$ having different gasification extents.

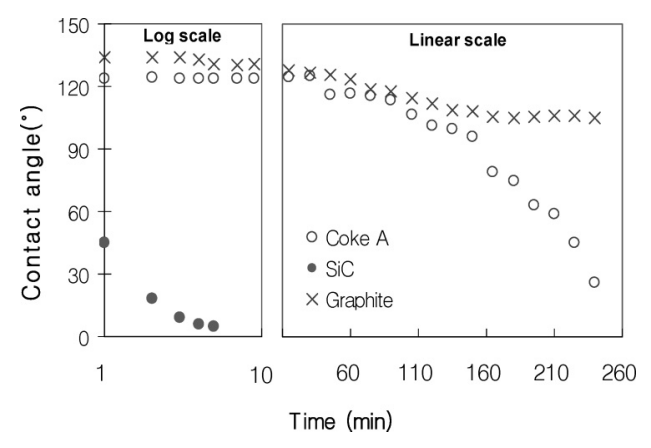

Fig. 5. Variation of contact angle of Slag 2 with time on substrates of unreacted Coke A, synthetic graphite and $\mathrm{SiC}$ at $1500^{\circ} \mathrm{C}$.

Figure 5 indicates wettability of same Slag 2 with synthetic graphite, which displayed non-wetting behaviour for the whole duration of test. Strong non-wetting nature of Slag 2 with graphite can be attributed to small amount of ash content being $0.01 \%$. Therefore, wettability of slag/graphite system further demonstrates the significance of ash content of carbonaceous material on their wettability towards slag. Our results are also in consistent with previous results for coal-chars. ${ }^{9)}$

Deposition of SiC could occur on slag/coke interface (Eq. (7)) and hence could affect the wettability of slag on coke. Therefore, in order to test the possible consequences of $\mathrm{SiC}$ on the wettability of slag/coke system, wettability test of Slag 2 with $\mathrm{SiC}$ substrate was conducted. Figure 5 also shows the variation of contact angle of Slag 2 on a $\mathrm{SiC}$ substrate with time. Contact angle of $\mathrm{SiC}$ drops rapidly such that it approaches 20 degrees within 2 min. Figure 5 clearly demonstrates the excellent wetting characteristics of $\mathrm{SiC}$ with slag in the tested conditions and consistent with past related studies. ${ }^{21)}$

\subsection{Measurements of Interfacial Reactions}

The reduction of metal oxides such as iron oxide and silica present in both slag and coke, and the oxidation of coke are expected to occur in the interfacial region. Figure 6 plots the amount of $\mathrm{CO}$ and $\mathrm{CO}_{2}$ gases (moles) released with time during in-situ heating of four coke samples in the absence of slag droplet. Figure 6 shows that coke sample with higher ash content generated greater amount of gases. Often, $\mathrm{CO}$ and $\mathrm{CO}_{2}$ release during in-situ heating of carbonaceous materials is attributed to reaction of the adsorbed oxygen on the surface with carbon. ${ }^{22)}$ However, the amount of $\mathrm{CO}$ and $\mathrm{CO}_{2}$ gases generated increased with ris-

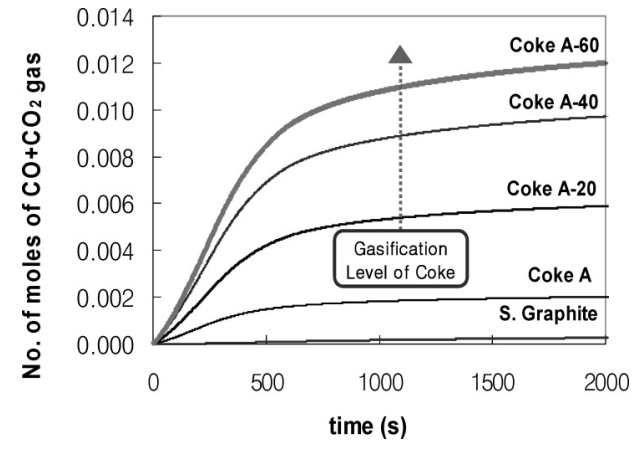

Fig. 6. Amount of $\mathrm{CO}$ and $\mathrm{CO}_{2}$ gases (moles) generated during in-situ reduction of oxides in ash by carbon in cokes of various ash content prepared by partial gasification (0-60\%: Coke A, Coke A-20, Coke A-40 and Coke A$60)$ and synthetic graphite at $1500^{\circ} \mathrm{C}$.

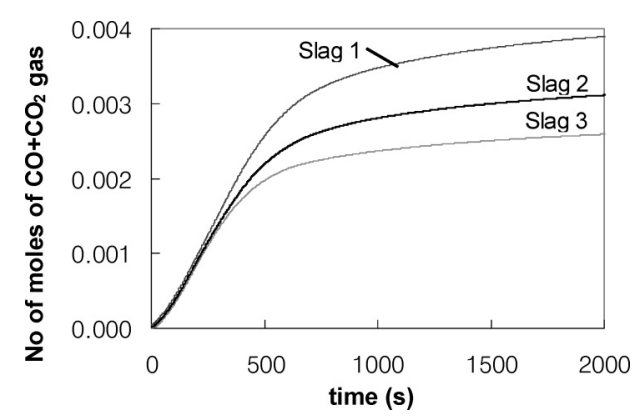

Fig. 7. Comparison of $\mathrm{CO}$ and $\mathrm{CO}_{2}$ gases (moles) released with time during reactions of Slags 1, 2, and 3 with Coke A at $1500^{\circ} \mathrm{C}$.

ing ash content of coke suggesting that in-situ reduction of coke oxides such as iron oxide and silica are primarily responsible for gas generation. On the other hand, the $\mathrm{CO}$ and $\mathrm{CO}_{2}$ gases released during heating of synthetic graphite were insignificant when compared to coke samples, which can be attributed to negligible ash content of graphite. The temperatures at which the characteristic fusibility shapes are formed are measured using ASTM Standards D 1857 test. From the result of this analysis, the deformation temperature of ash fusion in coke is estimated to be $1250^{\circ} \mathrm{C}$. Consequently, under our test conditions, most of ash in coke samples is expected to be the liquid state, which could further promote the reduction of coke ash oxides. The result implies that extent of in-situ reaction between carbon and ash components of coke increases with increasing ash content in the coke sample.

Figure 7 compares the total amount of $\mathrm{CO}$ and $\mathrm{CO}_{2}$ gases (moles) released with time during the reactions of slag samples with Coke A. Almost linear increase in the initial stages of contact followed by a steady values of $\mathrm{CO}$ and $\mathrm{CO}_{2}$ gases was typical to all these plots. Molar data of $\mathrm{CO}$ and $\mathrm{CO}_{2}$ gases was converted into the equivalent number of moles of oxygen removed from the slag oxides. When analyzing the amount of oxygen removed from slag/coke system, volume of $\mathrm{CO} / \mathrm{CO}_{2}$ gases released during in-situ reduction of coke oxides was subtracted (based on Fig. 6) from the total volume of gases generated during coke/slag reactions (Fig. 7) in order to compare the gases associated with reduction of oxides in slag only. It may be noted that a small amounts of adsorbed gases in the coke could also contribute in the reduction of slag oxides. However, in our set up most of the adsorbed gases are expected to be released instantaneously out of system and consequently might not have a significant contribution on 


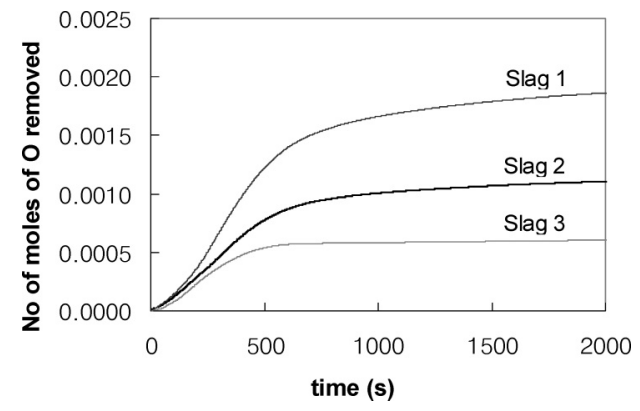

Fig. 8. Comparison of number of oxygen moles removed from Slags 1, 2, and 3 by carbon in Coke A, with time during the reactions at $1500^{\circ} \mathrm{C}$.

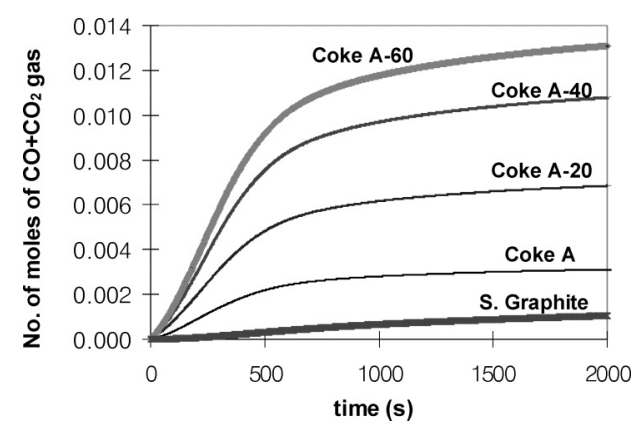

Fig. 9. Comparison of $\mathrm{CO}$ and $\mathrm{CO}_{2}$ gases (moles) released with time during reactions of Slag 2 and four coke samples varying ash content at $1500^{\circ} \mathrm{C}($ Coke A, Coke A-20, Coke A-40 and Coke A-60). The result for graphite reaction with the same Slag 2 is also provided.

silica reduction from slag when compared to other factors. Thus, Fig. 8 plots are based on the $\mathrm{CO} / \mathrm{CO}_{2}$ data associated with reduction of slag oxide alone after excluding the insitu contribution of gas release from coke alone.

Figure 7 further shows that with decreasing basicity of slag, the amount of $\mathrm{CO}$ gas liberated increases, and can be attributed to increasing amounts of $\mathrm{SiO}_{2}$ in three slag samples, being highest in Slag 1. Figure 8 depicts variation of number of moles of oxygen removed from the slag oxides. Figure 8 shows that the rate of reduction, indicated by the slope of initial straight line, increases with decreasing basicity of the slag. Low basicity slag such as Slag 1 indicated higher rates compared to the reaction rates of higher basicity Slags 2 and 3. Our results are in agreement with the past findings on slag/char where the kinetics of reduction was found to depend on the silica content of slag. 9) As all slags have the same iron oxide content, it is reasonable to conclude that differences in reduction behaviour and the kinetics are primarily attributed to the silica content in slag and its associated reduction.

In Fig. 9, the amount of gases $\left(\mathrm{CO}\right.$ and $\left.\mathrm{CO}_{2}\right)$ released is plotted against time during interaction of Slag 2 with 4 samples of Coke A varying in ash content. Even though, gases in Fig. 9 could include adsorbed gases from coke, their contribution is not expected to be significant when compared to carbothermal reduction of ash components. Coke sample (Coke A-60) with high ash content provided relatively higher amount of $\mathrm{CO}$, indicating a higher extent of reaction. The amount of $\mathrm{CO}$ released was found to decrease as the ash content of coke samples decreased. The cumulative amount of $\mathrm{CO}$ and $\mathrm{CO}_{2}$ gases for highest ash containing sample (Coke A-60) was nearly 4 times of the amount removed from the Coke A (least ash content). Compared with Fig. 6, the reduction reaction becomes more intensive in the presence of a slag due to additional

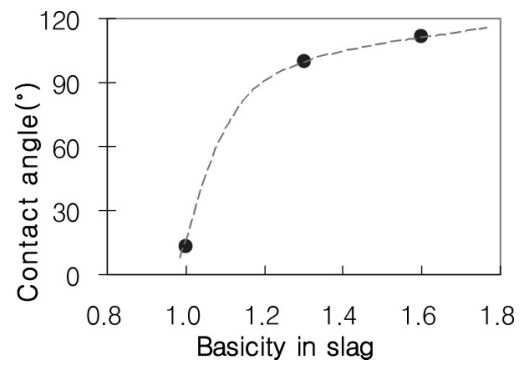

Fig. 10. Correlation between basicity in slag and contact angle demonstrating the effect of basicity of slag on wettability with coke (after $135 \mathrm{~min}$ of interaction between Slags 1,2 , and 3 with Coke A).

contribution to gases released as a consequence of reduction of slag oxides by coke carbon. The results of graphite interaction with Slag 2 suggest that in accordance with its non-wetting nature of this system, the amount of gases released due to graphite/slag reactions was negligible. These results demonstrate significant influence of ash content of carbonaceous materials including that of coke, on the reduction rate (moles per unit time) of oxides present in the slag phase. The dependence of the extent of reduction with ash content in coke is evident from the results obtained for the interaction of the slag on coke of various chemistries.

\section{Discussion}

\subsection{Influence of Slag and Coke Properties on Wetta- bility of Slag/Coke System}

Wettability is often quantified in terms contact angle. In a reactive system, wetting is dynamic, and at high temperatures depends on many factors such as chemical reactions, solute segregation, new phase formation, etc. ${ }^{8)}$ As the main aim of this study was to identify the influence of chemical composition of slag and its reaction with coke on wettability, the discussion will be restricted to the factors relating to coke and slag composition. In previous section, it was clearly indicated that wetting and reaction kinetic were dependent on slag and coke chemistry. Figure 10 summarizes the correlation between slag basicity and contact angle to illustrate that wettability of slag/coke system improves with decreasing basicity or increasing $\mathrm{SiO}_{2}$ content of slag. The association between silica content of slag and contact angles can be related to the different extents of reduction of slag oxides such as silica as confirmed by measurement of $\mathrm{CO}$ gas evolution during the reaction. Since the same amount of iron oxide is present in all slags, lower values of contact angle were related to increased reduction of $\mathrm{SiO}_{2}$ in slags.

In the blast furnace, during gasification the ash content of coke changes continuously. In previous section, it was shown that high ash content of coke leads to improvement in wetting propensity of slag. Figure 11 shows the correlation between contact angle and ash content of coke after interaction of Slag 2 at $1500^{\circ} \mathrm{C}$. For comparison, a contact angle data for synthetic graphite is also plotted in Fig. 11. It can be clearly seen that the wettability improves with increase of ash content, that is, increase of reducible oxide content such as iron oxide and silica in coke ash as indicated in Table 3. Thus, this improvement of wetting could be similar to that effect of slag basicity on wettability with coke as discussed further in the next section. The results imply that a coke with high ash content could improve slag permeability. However, for practical purpose in blast furnace operation, it is difficult to select a coke with a high ash 


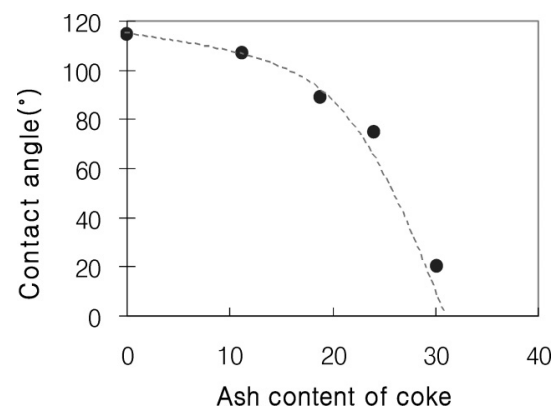

Fig. 11. Correlation between contact angle and ash content of coke after $105 \mathrm{~min}$ of interaction with Slag 2 at $1500^{\circ} \mathrm{C}$. (Ash $=0 \%$ is synthetic graphite used as a reference.)

content to improve the wettability with slag due to other associated adverse effects on the quality of molten iron and coke physical properties such as DI (Drum Index, used for coke degradation measurement related with coke intensity) and CSR (Coke Strength after Reaction). Especially coke DI and CSR are the main factors to influence the drainage of molten slag and iron by controlling liquid permeability at the hearth of the blast furnace, and consequently they have close relationship with blast furnace productivity and the life of hearth refractory. Therefore, for controlling slag liquid permeability, as implied from slag wettability with coke in this study, the adjustment of slag composition is expected to be more favourable for practical blast furnace conditions rather than control of coke ash content. The results regarding influence of coke ash content from different gasification levels on wettability is applicable to slag/coke interaction phenomena occurring at different heights of the blast furnace. Ash content of coke could increase up to approximately $20-30 \%$ by gasification with descent of coke in a blast furnace. ${ }^{20)}$ Thus, from the results, coke in the hearth of the blast furnace, namely deadman coke, could be expected to have better wettability with molten slag, compared with coke layer at cohesive zone present in the belly and bosh of the blast furnace.

\subsection{Mechanisms of Dynamic Wetting of Slag/Coke System}

The coke-slag is a complex reactive system in which many reactions and interactions occur which have different implications on the modification of contact angle. For example, dissociation of surface oxides, chemical dissolution of the solid in the melt and interfacial adsorption of reactive solutes, and formation of a wettable interfacial phase could decrease contact angle and promote wettability. Moreover, the intensity of these interactions are also dependent on time. Thus, no single model or mechanism is sufficient to provide a complete understanding of the wetting measurements. Coke-slag wetting can be distinctly divided into two groups namely initial steady state in which contact angle does not change with time significantly approximately for one hour, and dynamic stage in which contact angle changes rapidly with time (Figs. 2 and 4).

During steady state condition, the reduction reaction at the interface is completed within a short time of the order of 10 min (Figs. 7 and 8) while silica transport and growth of interfacial product such as $\mathrm{SiC}$ continues that results in observed dynamic wetting phenomenon. The variation in the contact angle in the initial steady state of all the slags can be explained on the basis of free energy changes associated with the interfacial reduction reaction of silicon and iron oxide in slags, and also the reduction of the similar ox- ides in coke ash present at the interface. In order to illustrate the mechanisms of dynamic of wetting of coke/slag system, interfaces of Slag 1 and Coke A was examined in detail. The reduction of metal oxides at interface is accompanied by a change in the chemical composition of the slag droplet and the substrate, and often also with the formation of new chemical phases at the interface. When solid carbon substrate is an active participant in the reduction reaction, the free energy during the reactions is expected to reduce the interfacial energy. ${ }^{8}$ However, with the initial contact angle being high, generally $>100^{\circ}$, the contact angle did not decrease significantly in the steady state as expected on the basis of the reduction in interfacial energy. It may be noted that due to progressive depletion of silica and iron oxide from slag, the surface tension of the slag can increase. ${ }^{3)}$ Consequently, in the initial $60 \mathrm{~min}$, due to two opposing factors namely decreasing interfacial tension (due to free energy) and increasing surface tension (due to depletion of $\mathrm{SiO}_{2}$ and $\mathrm{Fe}_{2} \mathrm{O}_{3}$ ), the contact angle is not changed significantly. A similar trend was also noted in during slag reactions with char and graphite. 5,9$)$

Subsequent rapid changes of contact angles after one hour are dictated by progressive decrease in the interfacial energy, and are related to the of kinetics of reduction reactions, mass transfer and subsequent interfacial phase formation. ${ }^{4)}$ Due to reactive and dynamic nature of slag/carbon system, at a given temperature, the chemical composition of the interface changes continuously with time. For the good wetting Slag 1, the interfacial basicity was found to be low, as indicated by the presence of high concentration of silica at the interface. This resulted in a concentration gradient of silica from the bulk phase of slag droplet towards the interface. Thus, the interface composition is continuously changed with time as a result, of gradual mass transfer from the bulk to the interface. It may be noted that silica transfer to the interface could be further enhanced due to rapid mass transfer near the periphery zone of molten slag, which could even have a greater effect when compared to bulk phase transfer of silica. At the beginning of reaction, the reaction occurs at a high rate and there was no significant change in contact angle as opposing factors are balanced. However, as the reaction slows down at the interface, the rate of supply of $\mathrm{SiO}_{2}$ from the bulk to the interface exceeds the rate of consumption of the oxides at the interface. The interfacial tension at the solid/liquid interface therefore decreases continuously, resulting in a decrease in contact angle. It may be noted that even though reduction reaction are stopped within $10 \mathrm{~min}$, the rapid decline in contact angle is reflected only after $1 \mathrm{~h}$ as interfacial product such as $\mathrm{SiC}$ is initially expected to nucleate only on the limited sites at the coke-slag interface. Eventually, the interfacial phases would grow with time and the slag would only start responding to this modified interface after that time. But since, the $\mathrm{SiO}_{2}$ content is decreasing, and the effect of opposing factors does not permit any change in the first $1 \mathrm{~h}$. Beyond that time, as explained earlier, the effect of interfacial tension decrease is predominant, and the contact angle is seen to decrease. Extent of silica reduction is strongly influenced by the amount of silica in the slag as well as coke, and is dictated by reduction kinetics. High basicity or low silica slag such as Slag 3 indicated the least extent of silica reduction. Therefore, Slag 3 is expected to provide least amount of deposition of interfacial phase such as SiC. Consequently, the wettability of Slag 3 did not change even after prolonged contact (Fig. 2), and can be attributed to the lack of sufficient growth of $\mathrm{SiC}$ layer at the interface. 


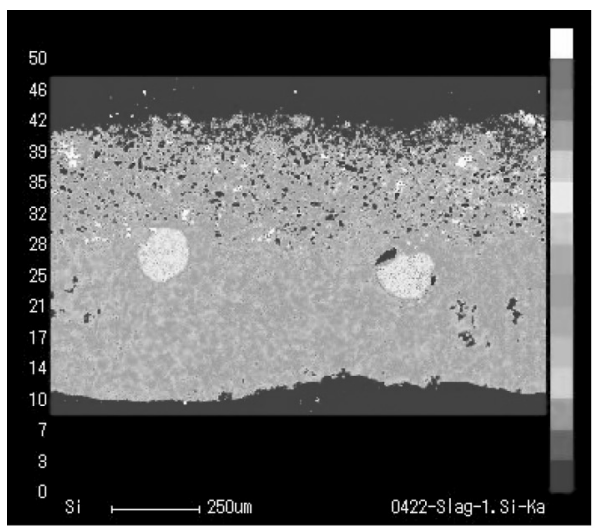

(a)

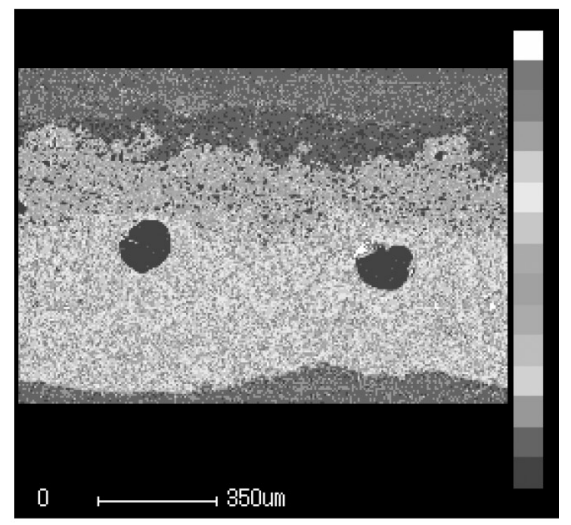

(b)

Fig. 12. EPMA (Electron Probe Micro Analysis) image illustrating silicon and oxygen distribution at the interface of Slag 1 and Coke A, after $135 \mathrm{~min}$ interaction at $1500^{\circ} \mathrm{C}$. In both the images, the upper blue region indicates coke phase, and the green, red and yellow areas of lower part are the bulk phase of slag droplet. Two circular yellow deposits indicate reduced iron particles containing silicon.

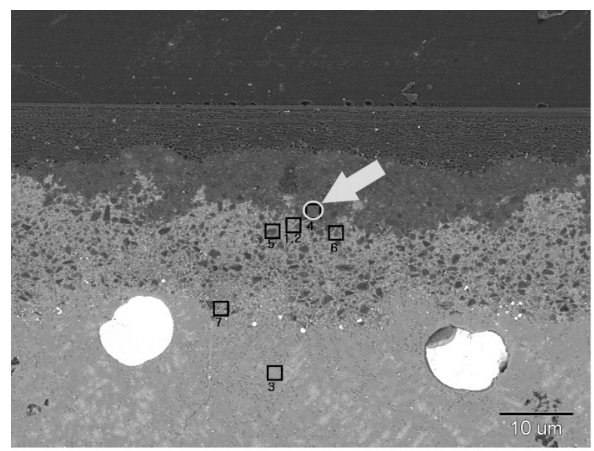

(a)

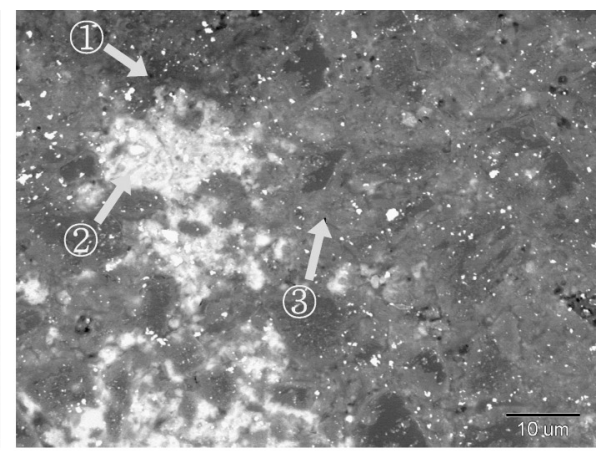

(b)

Fig. 13. (a) FESEM image of the interface of Slag 1 and Coke A, $135 \mathrm{~min}$ after interaction at $1500^{\circ} \mathrm{C}$, (b) magnified FESEM image of circular region indicated by the arrow in (a). The upper area of dark black color indicates coke phase, and the lower gray area indicates slag phase while the intermediate layer is the reacted phases at the interface.

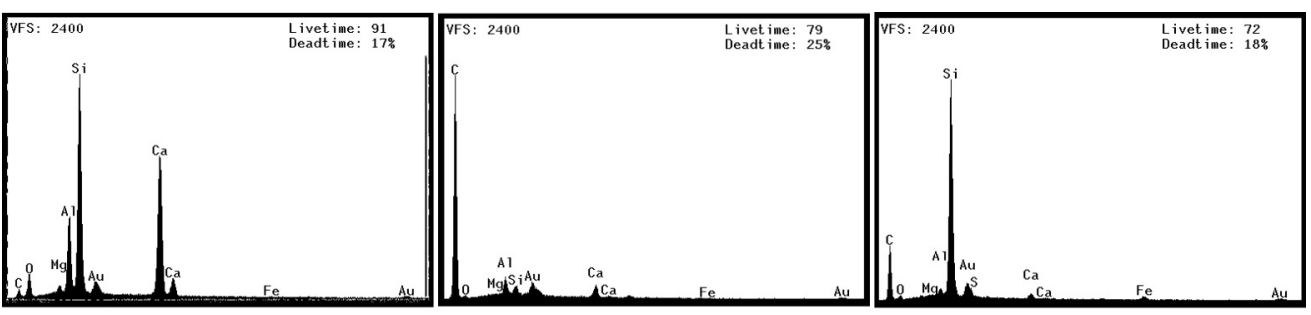

(a)

(b)

(c)

Fig. 14. (a) EDS composition of white regions in Fig. 13(b) (point (1) indicating typical bulk composition of slag droplet, (b) black zones in Fig. 13(b) (point (2)) representing typical carbon rich coke phase, (c) gray regions in Fig. 13(b) (point (3) possibly representing the presence of SiC.

Figure 12 shows the EPMA images of a small part of interface of Slag 1 and Coke A illustrating the silicon and oxygen distribution. Careful examination of silicon and oxygen concentration and their association in Fig. 12, suggest that $\mathrm{SiO}_{2}$ was consumed and depleted during reduction reaction by coke carbon at the interface layer. Therefore, the concentration gradient of silica across the top regions of slag droplet towards the interface could be related to mass transfer of $\mathrm{SiO}_{2}$ from bulk phase towards the interface.

Reduction of silica and presence of $\mathrm{SiC}$ at the interface have been believed to contribute to increased wetting of carbonaceous material with time by blast furnace slag. ${ }^{5,11,19)}$ Therefore, it is reasonable to assume that $\mathrm{SiC}$ was formed in our coke/slag interface, which could slow down reduction reaction of oxides, and decrease interfacial tension, consequently decreasing the contact angle. Excellent slag wetting on SiC substrate as shown in Fig. 6 also illustrates that $\mathrm{SiC}$ deposition formed at the interface decreases interfacial tension, leading to wetting improvement.

Figure 13(a) shows FESEM image of a small part of the interface of Slag 1 and Coke A after $135 \mathrm{~min}$ of contact at $1500^{\circ} \mathrm{C}$, while Fig. 13(b) shows the magnified FESEM image of circular regions pointed by an arrow in Fig. 13(a). The interface shown in Fig. 13(b) consists of mixed zones of slag, coke and also new phase formed by slag/coke reaction. Figures 14(a), 14(b), 14(c) provides the EDS results 
of typical composition of three spots shown as (1), (2) and (3) respectively in Fig. 13(b). Figure 14(c) shows a shows strong peaks of silicon and carbon (3) spot in Fig. 13(b)). The relative ratio of silicon and carbon peak intensities of this phase is similar to that of SiC indicating the possibility of the presence of silicon carbide ( $\mathrm{SiC}$ ) formed by coke/slag reaction.

With increasing time, as the contact angle drops even a small decrease in interfacial energy is sufficient to cause significant further decrease in contact angle, as is evident from the relatively faster decrease in contact angle, shown in Fig. 2, at times after 45 min of melting for the good wetting cases of Slag 1 on Coke A. The contact angle of molten oxide glasses is known to be very sensitive to small variations in interfacial energies, particularly at low contact angles such that a small \% of change of interfacial energy could drastically affect wetting interactions. ${ }^{23)}$ This explanation is also consistent with that used for explaining dynamic wettability of char/slag system. ${ }^{\text {) }}$

\subsection{Kinetics of Interfacial Reactions of Slag/Coke Sys- tem}

In previous section, it was shown that reduction reactions of slag oxides by coke carbon, as well as in-situ reduction of coke oxides had a strong effect on the wetting characteristics of slag/coke system. Particularly, the amount of metal oxides such as iron oxide and silica present in slag determines the extent of interfacial reaction. The equivalent number of moles of $\mathrm{FeO}$ or $\mathrm{SiO}_{2}$ reduced was estimated from the molar units of oxygen removed from system as a function of time. It is assumed that iron oxides in a slag system are preferentially reduced ahead of $\mathrm{SiO}_{2}$. This assumption is valid since, the analysis of the residual oxides in slag phases indicated that most of the iron oxide was consumed, while majority of silica was still present in the slag even after prolonged contact of one hour with coke. Therefore, the similar values of $\mathrm{CO} / \mathrm{CO}_{2}$ gases released (Fig. 7) especially in first $500 \mathrm{~s}$ can be attributed to iron oxide reduction as all slags have similar iron oxide levels and are believed to be preferentially reduced in the presence of silica. ${ }^{4,9)}$

The reduction of silica in the slag was considered to occur by the equations of (7) and (9). These reactions are believed to proceed through the intermediate step of the formation of $\mathrm{SiO}$ gas, which is further reduced by carbon or solute carbon dissolved in iron to silicon. Often, the reaction rates of the reduction of $\mathrm{SiO}_{2}$ to $\mathrm{SiO}$ gas had been calculated by assuming that most of the $\mathrm{SiO}$ gas was allowed to escape the system, providing little opportunity for further reduction of $\mathrm{SiO}$ gas by $\mathrm{CO}$ gas or solute carbon. ${ }^{24)} \mathrm{On}$ the other hand, if most of the $\mathrm{SiO}$ is allowed to remain in the system, and provided sufficient opportunity for subsequent reduction of $\mathrm{SiO}$, it would provide more useful approach to calculate the reaction rate based on overall reduction from $\mathrm{SiO}_{2}$ to $\mathrm{Si}$ or SiC (Eqs. (7) and (9)). Based on these equations, with two atoms of oxygen present in $\mathrm{SiO}_{2}, 1 \mathrm{~mol}$ of $\mathrm{SiO}_{2}$ reduced from the system corresponds to $2 \mathrm{~mol}$ of oxygen removed. In the present study, it is seen that the composition of the final slag as available from the EPMA analysis (mapping and point analysis), could be explained reasonably by performing mass balance of silica, assuming overall reduction as per Eqs. (7) and (9). But, there is still an error associated with the small percentage of $\mathrm{SiO}$ that is escaping form the system, which can be expected with small difference of silica percentage in slag between results calculated by mass balance and analysed by EPMA. Nevertheless, for

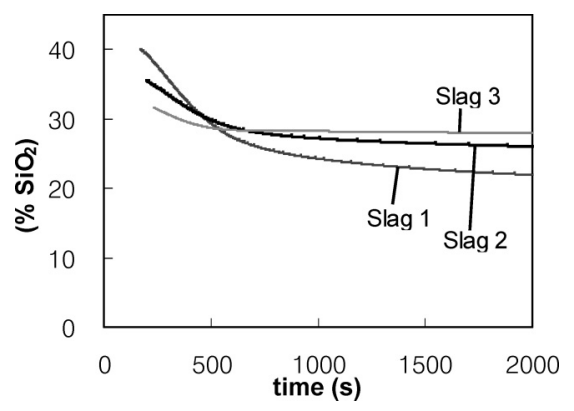

Fig. 15. Variation of residual $\mathrm{SiO}_{2}(\%)$ in slags during their interaction with Coke A.

Table 5. Overall reaction rates for the reduction of silica during the interaction of slags with coke A, at $1500^{\circ} \mathrm{C}$.

\begin{tabular}{|c|c|c|c|}
\hline & Slag 1 & Slag 2 & Slag 3 \\
\hline $\begin{array}{c}\mathrm{R} \times 10^{-6} \\
\left(\mathrm{moles} / \mathrm{cm}^{3}-\mathrm{s}\right)\end{array}$ & 15.6 & 9.0 & 5.4 \\
\hline
\end{tabular}

purpose of calculation, it is assumed that overall reduction $\mathrm{SiO}_{2}$ in slag proceeds as per Eqs. (7) and (9).

Figure 15 shows the amount of residual silica in the system as a function of time, during the interaction of slags and coke. This behaviour of silica reduction is similar to that observed during carbothermic reduction of silica, ${ }^{25}$ ) The rate and extent of silica reduction in case of Slag 1 are higher than other slag samples, which could be attributed to greater contribution of silica from Slag 1 droplet to silica levels at the interfacial region that participates in the reduction reactions. Initial delay of onset of silica reductions suggests the preferential reduction of $\mathrm{Fe}_{2} \mathrm{O}_{3}$ present in slag, which is expected to proceed prior to silica reduction. With significant amounts of silica still remaining unreduced, the interfacial region is not deprived of oxygen. The reduction of silica of Slag 3 takes a little bit longer time to start when compared to other slags. The residual silica in slag becomes steady after $1000 \mathrm{~s}$ suggesting that silica reduction becomes slow or stops after some time. This is most likely linked to the deposition of new phases formed at the interface such as metallic iron and silicon carbide, which could progressively inhibit the access of carbon to $\mathrm{SiO}_{2}$ into interface. Faster reaction rate of reduction of Slag 1 compared to the reaction rates of other slags with lower silica content imply that silica content of slag has a strong influence on the reduction of silica at interface.

The slope of linear portion of the graphs (Fig. 15) at the initial period of the reduction was used to calculate the reaction rate. From the slopes obtained from the graph, the overall reaction rate was calculated using Eq. (10).

$$
R_{\mathrm{SiO}_{2}}=\left(S_{\mathrm{SiO}_{2}} / 100\right) \times \rho_{\text {slag }} / \mathrm{MW}_{\mathrm{SiO}_{2}}
$$

Where, $R_{\mathrm{SiO}_{2}}=$ reaction rate for $\mathrm{SiO}_{2}$ in $\mathrm{mol} / \mathrm{cm}^{3} \cdot \mathrm{s}$, $S_{\mathrm{SiO}_{2}}=$ slope of the graph, in percent of $\mathrm{SiO}_{2}$ per second, $\mathrm{MW}_{\mathrm{SiO}_{2}}=$ molecular weight of $\mathrm{SiO}_{2}, \rho_{\text {slag }}=$ density of the slag in $\mathrm{g} / \mathrm{cm}^{3}$.

As the silica reduction was the predominant reaction, the reaction rates are only shown for the reduction of silica, and provided in Table 5. Comparison of reaction rates in Table 5 clearly shows that with increasing silica content in slags, the reaction rate increases, and demonstrates that the reaction rate is influenced by the concentration of silica in the slag. This is in good agreement with Mehta et al., ${ }^{9)}$ who calculated the reaction rate of slag (basicity $1.22, \mathrm{MgO}$ $5 \mathrm{wt} \%$ ) reacted with natural graphite (ash $11.4 \mathrm{wt} \%, 69 \%$ $\mathrm{SiO}_{2}$ in ash). The reaction rate is $13.5 \times 10^{-6} \mathrm{~mol} / \mathrm{cm}^{3} \cdot \mathrm{s}$ at 
$1500^{\circ} \mathrm{C}$, which has a value between those of Slag 1 and Slag 2, considering slag basicity and similar ash content of natural graphite with Coke A, supporting that the reaction rate is dependent on silica content in slag, and silica/ash content in carbonaceous material

\section{Conclusions}

Interfacial phenomena associated with metallurgical coke sample from an operating blast furnace and synthetic slag samples simulating typical slag chemistry and temperature $\left(1500^{\circ} \mathrm{C}\right)$ of lower zone of the blast furnace, were investigated in a laboratory furnace. The dynamic wetting was measured by using classical approach by preparing sessile drop of slag on a coke substrate through contact heating at $1500^{\circ} \mathrm{C}$, while off gases were monitored by infrared analyser to measure reduction kinetics of metal oxides at the coke/slag interface. On the basis of this study, following conclusions were made.

(1) The slag/coke wetting was found to be enhanced rapidly with decreasing basicity of slag in the tested range from 1 to 1.6. Coke sample did not display any wetting with high basicity slag even after a long exposure to slag. The wetting tendency of slag with coke was found to improve with increasing extent of coke gasification as a consequence of increased ash content.

(2) On the basis of chemical composition of gases $(\mathrm{CO}$ and $\mathrm{CO}_{2}$ ) released during slag/coke reaction, the study showed that wetting behaviour of slag/coke was strongly related to the kinetics of silica reduction at the interface, and was also dependent on the oxide chemistry of both slag as well as coke. High coke ash content and relatively higher amounts of silica in the coke as well as in the slag promoted the kinetic of reduction at the interface as well as wetting. Consequently, slag/coke wetting was rapidly improved with decreasing basicity of slag and increasing ash content of coke.

(3) The wetting tendency of graphite with slag was found to be poor, and so was the evidence of any significant reduction of interface oxides, and was mainly attributed to negligible ash content of graphite. The chemical analysis of slag droplets further supported the strong influence of slag chemistry on the kinetics of wetting by indicating higher reaction rate of silica reduction among the slag samples with higher silica content.

(4) The EPMA analysis of slag/coke interface confirmed the progressive decline in the silica concentration from slag bulk phase to the interface. Consequently, dynamic wetting of slag/coke system could have been be controlled by mass transfer of silica to interface. The onset of dynamic wetting takes place much after the reduction reactions have reached a steady state, as a result of deposition of reaction products in the interfacial region. FESEM analysis of the slag/coke interface suggests presence of metallic iron and $\mathrm{SiC}$ deposition, formed by reaction between reducible oxides and carbon in coke. Since SiC wetting by slag was seen to be excellent in our system, $\mathrm{SiC}$ deposit at interface could lead to improvement in coke/slag wetting.
In this study, it is illustrated that coke/slag interfacial phenomena leading to wetting improvement are attributed to the increased reduction of reducible oxides, i.e. silica, by carbon at the slag/coke interface. Furthermore, decreased interfacial tension by chemical deposition of silicon carbide leads to improvement in wetting of coke/slag systems, when reaction slows down. The study implies that in addition to slag viscosity, coke/slag interaction could also have significant impact on control of liquid permeability of the blast furnace. Further research is required to develop a slag fluidity index incorporating the wettability behaviour slag/coke system at different locations in a blast furnace, and subsequent validation by blast furnace operating experience.

\section{Acknowledgements}

The authors acknowledge the industrial sponsor, POSCO (Pohang Iron and Steelmaking Company, Republic of Korea) for supporting this project.

\section{REFERENCES}

1) S. H. Yi and W. W. Huh: Int. Blast Furnace Lower Zone Symp., The Australian Institute of Mining and Metallurgy, Illawara, Australia, (2002), 21-1.

2) Y. S. Lee, J. R. Kim and D. J. Min: Proc. of Science and Technology, of Innovative Ironmaking for Aiming at Energy Half Consumption, ISIJ, Tokyo, (2003), 153.

3) Verin Deutsher Eisenhuttenleute (VDEh) (ed): Slag Atlas, 2nd ed., Verlag Stahleisen GmbH, D-Dusseldorf, Germany, (1995), 313.

4) A. S. Mehta and V. Sahajwalla: Scand. J. Metall., 29 (2000), No. 1, 17.

5) A. S. Mehta and V. Sahajwalla: ISIJ Int., 43 (2003), 1512.

6) T. D. Blake: Wettability, ed. by J. C. Berg, Marcel Dekker Inc., USA, (1993), 251.

7) Y. T. Philos: Trans. R. Soc., London, 95 (1805), 65.

8) J. A. Pask: Ceram. Bull., 66 (1987), 1587.

9) V. Sahajwalla, A. S. Mehta and R. Khanna: Metall. Mater. Trans. B, 35B (2004), No. 1, 75.

10) W. Pan, M. Sano, M. Hirasawa and K. Moro: ISIJ Int., 31 (1991), 358.

11) Blast Furnace Phenomena and Modeling, ed. by Y. Omori, Elsevier Applied Science Publishers Ltd., UK, (1987), 559.

12) R. M. Patalski, R. Gray, O. Roanes and S. J. Todd: Electric Arc Furnace Conf. Proc., ISS, Warrendale, PA, USA, (1995), 15.

13) V. Croft: Ironmaking Steelmaking, 7 (1980), 116.

14) A. K. Biswas: Principles of Blast Furnace Ironmaking, Cootha Publishing House, Brisbane, Australia, (1981), 1.

15) D. J. Min and R. J. Fruehan: Metall. Trans. B, 23B (1992), 29.

16) N. Siddiqi, B. Bhoi, R. K. Paramguru, H. S. Ray, V. Sahajwalla and O. Ostrovski: High-Temp. Mater. Process., 16 (1997), 213.

17) M. S. Bafgi, Y. Ito, S. Yamada and M. Sano: ISIJ Int., 32 (1992), 1280.

18) C. Wu and V. Sahajwalla: Metall. Mater. Trans. B, 29B (1998), 471.

19) H. Towers: Trans. J. Brit. Ceram. Soc., 55 (1954), 180.

20) K. Kojima, T. Nishi, T. Yamaguchi, H. Nakama and S. Ida: Trans. Iron Steel Inst. Jpn., 17 (1977), 401.

21) E. Raask: Mineral Impurities in Coal Combustion, Hemisphere Publication, Washington, (1985), 67.

22) P. L. Walker, Jr., R. L. Taylor and J. M. Ranish: Carbon, 29 (1991), No. 3, 411.

23) B. J. J. Zelinski, J. P. Cronin, M. Denesuk and D. R. Uhlmann: Wettability, ed by J. C. Berg, Marcel Dekker Inc., USA, (1993), 467.

24) Y. Ebisawa, M. Tokuda and M. Ohtani: Final Report of the Committee of Blast Furnace Process and Its Modelling, ISIJ, Tokyo, (1982).

$25)$ D. Filsinger and D. B. Bourrie: J. Am. Ceram. Soc., 73, (1990), No. 6,1726 . 